\title{
A DIDÁTICA DOS JOGOS COMO FERRAMENTA NO PROCESSO ENSINO APRENDIZAGEM
}

\author{
1Sueli Karanauskas \\ 2 Dulcilene R.S Nascimento
}

\section{RESUMO}

Uma das grandes dificuldades no processo de ensino e aprendizagem são as escolhas dos métodos e em adequá-los a uma metodologia que seja efetiva, proporcionando avanços significativos. Tais questões sempre foram muito pensadas e discutidas entre educadores que apontam para que este processo tenha um olhar voltado a métodos que desafiem e motivem os alunos para que estes alcancem o conhecimento. Nesta perspectiva o presente trabalho aborda a importância dos jogos e brincadeiras no processo de alfabetização a fim de analisar se a forma de aprender se altera quando o método de trabalho é diferenciado. Reflete-se aqui acerca de alguns métodos abordados e direcionados em sala de aula como aulas expositivas, atividades xerocadas e atividades do livro, que são mais tradicionalmente utilizados confrontando com a utilização de outros métodos lúdicos com a inserção de jogos e brincadeiras correlacionados ao referencial teórico e que permitiram chegar às conclusões deste artigo. Discute-se aqui se o estudo realizado comprova que o lúdico deve fazer parte dos ambientes escolares e se a criança aprende com mais naturalidade quando os conteúdos propostos são aplicados com a utilização de jogos e brincadeiras. Entende-se que o brincar faz parte do cotidiano do ser humano. Mas qual será a relação deste fato na escolha dos métodos de ensino para proporcionar ou auxiliar no processo de alfabetização? É possível através dos jogos e brincadeiras aumentar a tensão dos alunos e reduzir a indisciplina? Essas questões proporcionarão reflexões para possíveis intervenções para um aprendizado mais prazeroso e significativo.

Palavras-chave: Jogos, Brincadeiras. Alfabetização. Aprendizagem. 


\section{ABSTRACT}

One of the great difficulties in the teaching and learning process is the choices of the methods and in adapting them to a methodology that is effective, providing significant advances. Such issues have always been much thought and discussed among educators who point out that this process has a look at methods that challenge and motivate students to achieve knowledge. In this perspective, this paper addresses the importance of games and games in the literacy process in order to analyze whether the way of learning changes when the working method is differentiated. We will reflect on some methods addressed and directed in the classroom such as expository classes, xerocada activities and book activities, which are more traditionally used in confrontation with the use of other playful methods with the insertion of games and games correlated to the theoretical framework and that allowed reaching the conclusions of this monograph. We will reflect on whether the study proves that the playful should be part of the school environments and whether the child learns more naturally when the proposed contents are applied with the use of games and games. We know that playing is part of the daily life of the human being, but what will be the relationship of this fact in the choice of teaching methods to provide or assist in the literacy process? Is it possible through games and games to increase student tension and reduce indiscipline? These questions will provide reflections for possible interventions for a more pleasurable and meaningful learning.

Keywords: Games, Games. Literacy. Learning.

1Sueli Karanauskas é Doutoranda em Educação pela Unilogos-EUA, Mestre pela Universidade São Marcos em Educação, Administração e Comunicação. Atualmente é diretora da Faculdade da Interativa de São Paulo, Professora e pesquisadora na aréa de Metodologias Ativas voltada ao ensino à distância e de estudos voltados a área de inclusão no Brasil.

2 Dulcilene R.S Nascimento Nascimento é PHD e Doutora em História, Mestre em Ciência Política, Cidadania e Governação, Mestre em Educação, Especialista em Metodologia do Ensino, Pesquisa com extensão em Educação e Licenciada em História. 


\section{INTRODUÇÃO}

Muitos são os métodos e técnicas de ensino utilizadas pelos educadores no processo de ensino e aprendizagem e quando se trata do processo de alfabetização enfrentamos muitos problemas em mudar os nossos paradigmas e em conseguirmos adequar uma metodologia que dê certo no processo de ensino e de aprendizagem de cada turma.

Durante muito tempo os métodos de ensino para alfabetizar se pautavam quase que unicamente em fazer cópias, cobrir pontilhados e em aprender o som das letras, quase não direcionando aos educandos a possibilidade de desafios para alcançar o conhecimento, muito menos colaborava para a motivação ao aprender. Ainda nos dias atuais estes métodos não foram totalmente excluídos da escola, e os jogos e brincadeiras, quase nunca são utilizados, principalmente, porque alguns professores priorizam unicamente conteúdos propostos pelo currículo e nessa questão ainda dizem que os alunos vão para escola aprender a ler e escrever, e não para brincar.

Porém há estudos científicos que comprovam uma grande necessidade de que as atividades lúdicas e os jogos sejam inseridos como métodos para o ensino a partir de meios concretos e com o uso de materiais lúdicos adequados à faixa etária e a aprendizagem de cada um. Sabemos que quando os jogos e as brincadeiras são utilizados como recursos didáticos para contemplar um conhecimento sobre determinada área na alfabetização, deixa de ser apenas uma simples brincadeira, proporcionando um estímulo para a assimilação dos conteúdos de uma forma mais fácil e prazerosa. Brincadeiras que levam nossas crianças ao desenvolvimento cognitivo precisam estar presentes dentro do ambiente escolar, mas é preciso conhecer o porquê de serem tão necessários ao processo de ensino e aprendizagem na alfabetização. Vemos uma imprescindível necessidade do educador em buscar fontes que tratem sobre 0 papel que os jogos e as brincadeiras têm (se têm) na fase da alfabetização.

Nesta pesquisa discutiremos em três fases para a compreensão da importância dos jogos e brincadeiras inseridos no processo de alfabetização. Sendo: as fontes que discutissem o quanto há importância de métodos mais 
lúdicos em sala de aula, a comparação entre métodos ditos tradicionais ou sem atividades lúdicas e para finalizar a aplicação de metodologias com a utilização de jogos e brincadeiras como meio de melhorar o processo de ensino e aprendizagem.

Sabemos que a criança na fase de alfabetização faz muito uso da imaginação e os jogos e brincadeiras proporcionam muito essas situações imaginárias que juntamente com materiais concretos se tornam possibilidades de métodos diferenciados para proporcionar o aprendizado. Desta forma traçaremos uma comparação para verificar como eram os métodos aplicados no passado e ainda entender os meios de como alfabetizar utilizando aulas mais lúdicas, pois, a cada ano que passa percebe-se o quanto as crianças estão desmotivadas com relação ao ambiente escolar, gostam muito da educação infantil, porque é muito voltada para os métodos lúdicos e ao ingressarem na educação básica as atividades são mais direcionadas aos livros e cadernos, utilizando-se assim poucos métodos com ludicidade

\title{
ALFABETIZAÇÃO E LETRAMENTO
}

Segundo Emília Ferreiro:

\begin{abstract}
"Alfabetização tem início bem cedo e não termina nunca. Nós não somos igualmente alfabetizados para qualquer situação de uso da língua escrita. Temos a facilidade de lermos determinados textos e evitamos outros. O conceito também muda de acordo com as épocas, as culturas e a chegada da tecnologia". Ferreiro (2003, p. 14)
\end{abstract}

A escola tem por dever oferecer aos alunos, desde os primeiros anos de escolarização, oportunidades de contato com a leitura e a escrita como práticas sociais, assim sendo "revestidas de significado, nas quais se busca a interação com o outro" (LEAL, MENDONÇA, MORAIS e LIMA, 2008, p. 6). Assim o processo de alfabetização deve promover tanto a apropriação do sistema de escrita quanto práticas de leitura. $\mathrm{Na}$ atualidade, pesquisadores e autores enfatizam a proposta de "alfabetizar letrando" e como prática para o letramento 
é utilizado o Sistema de Escrita Alfabética o qual a criança ainda começando a ser alfabetizada, ela já pode (e deve!) ler e escrever, mesmo que não domine as particularidades de funcionamento da escrita espera-se que os dois processos ocorram simultânea.

O professor é o agente motivador deste processo sendo ele o mediador e encantador da nova experiência nos pequenos alunos. Está comprovado através de estudos que alunos motivados se envolvem mais facilmente nas atividades e, consequentemente, estão mais dispostos a aprender. A alfabetização é um processo que vai além de decodificação de palavras e memorização de símbolos. Requer um conjunto de estruturas de pensamentos e habilidades psicomotoras que possibilita a compreensão de natureza conceitual e das formas de representação gráfica da linguagem.

Além da condição afetiva e motivadora a criança precisa desenvolver coordenação motora ampla, esquema corporal, coordenação viso motora, discriminação visual e auditiva e também orientação tempo-espacial. Quando brinca,

a criança tem oportunidade de desenvolver todas essas habilidades de forma criativa e divertida, tornando o aprender mais prazeroso e feliz. $\mathrm{Na}$ fase de alfabetização, aprender pode ser uma maravilhosa aventura, onde a criança se lança num mundo mágico desempenhando atividades com seriedade e motivação.

\section{OUTROS FATORES NECESSÁRIOS PARA FACILITAR AS AÇÕES DA ALFABETIZAÇÃO:}

Para facilitar o processo de alfabetização e proporcionar um ambiente alfabetizador, o professor deve fazer da sala de aula um espaço onde ricos estímulos de aprendizagem estejam sempre presentes. É um ambiente que promove um conjunto de situações de uso real de leitura e de escrita, em que os educandos têm a oportunidade de participar. Um ambiente alfabetizador não é apenas aquele em que aparecem diferentes tipos de texto, é mais que isso: é aquele que tem diferentes tipos de texto que são consultados frequentemente, 
com diferentes funções sociais. Eles devem ser substituídos de acordo com sua funcionalidade, além de estarem ao alcance do grupo.

Como já citado as atividades devem ser significativas e não simplesmente o brincar por brincar. Desta forma sempre prevendo um novo aprendizado como objetivo. Para favorecer uma alfabetização de qualidade, é necessário propor atividades de leitura e escrita que fazem sentido para as crianças e que as essas aconteçam de forma prazerosa, contextualizada, e de acordo com a realidade social dos educandos.

A capacitação docente é de extrema relevância para que o educador conheça o nível conceitual e as capacidades cognitivas de seus educandos para acreditar que níveis de conhecimentos variados constituem uma riqueza para o trabalho em sala de aula. O embasamento teórico através de estudos, leituras e cursos leva o alfabetizador a acreditar em seu trabalho, e que cada criança aprende no seu tempo, de acordo com suas diferenças e suas capacidades cognitivas.

A auto estima dos educandos também é um fator determinante para o processo de alfabetização, para reavivar a confiança em suas capacidades de dar conta dos desafios e dificuldades que terão de vencer.

As ações de intervenções no papel do alfabetizador preponderante se faz necessário para levar o educando a avançar no seu processo de construção de conhecimento. As intervenções devem ser problematizadoras, ou seja, devem colocar bons problemas para serem resolvidos pelos educandos.

Conhecer a gênese da leitura e da escrita compete ao educador competente que deve ser conhecedor profundo da gênese da língua escrita, para saber mediar as intervenções e atividades necessárias a obter sucesso no processo de alfabetização. Utilizando-se dessas estratégias o trabalho, sem dúvida, terá um resultado bastante compensador.

A realização de diagnósticos antes de iniciar o processo de alfabetização, é condição para o sucesso da aprendizagem da leitura e da escrita. Identificar os conhecimentos prévios e saber explorá-los é fundamental para qualquer aprendizagem. 


\section{ALFABETIZAÇÃO X JOGOS E BRINCADEIRAS}

Quando pensamos em educação devemos entender os vários processos de forma - ção do indivíduo, sendo física, mental, emocional e social. Tais aspectos tornam o trabalho docente mais árduo e intenso necessitando assim para melhor com- preendê-lo conhecer um pouco a ciência para que possamos desenvolver um pro cesso educacional com o propósito de compreender a necessidade de métodos dife- renciados para aquisição do conhecimento.

Afima Huizinga (2000) que o ser humano durante seu processo histórico sempre buscou brinquedos e brincadeiras que para satisfazer seus anseios psíquicos e emocionais. Para que uma civilização exista é preciso que se tenha certo lado lúdi- co, portanto brincar faz parte da natureza humana.

Desta forma a escola deveria proporcionar metodologias para viabilizar a ludicidade no processo de ensino e aprendizagem trazendo como método os jogos e brincadei- ras para que com o decorrer do tempo às aulas não passam a ser monótonas e pou- co atrativas para as crianças. No passado a escola brasileira enfrentava ainda mais problemas, pois era um lugar onde os conteúdos eram ensinados em forma de deco - ração e memorização, pouco se tinha de jogos e brincadeiras, os professores na grande maioria assumiam uma postura séria e autoritária e o silêncio imperava durante as as aulas sendo raros os momentos de brincadeiras e afetividade.

Desta forma se privilegiava a capacidade de demonstrar de uma forma teórica e geralmente através da escrita o que "aprenderam" durante as aulas, sendo assim não eram os métodos que apresentavam problemas quando a aprendizagem não ocorria com su- cesso e sim os próprios alunos os responsáveis por seu fracasso escolar.

Neste contexto Antunes (2008, p.13), afirma:

A escola antiga e obsoleta é aquela na qual o aluno a frequentava apenas para memorizar conceitos das disciplinas que o professor ministrava. Se fosse bom em Matemática, por exemplo, estava implícito que era bom professor, pouco importando se os alunos aprendiam de fato o conteúdo com ele. Quando a significação não ocorria, a culpa era sempre do aluno e por isso sua reprovação era incontestável ato de justiça. 
Estudos da história da Educação Brasileira nos trazem que jogos e brincadeiras no processo de ensino e aprendizagem eram bem pouco utilizados. As brincadeiras, normalmente faziam parte da vida das crianças fora da sala de aula como, por exemplo, nas brincadeiras de: correr pelas ruas, pular muros, brincar de pega- pega, amarelinha, entre tantas outras. E por isso era difícil um professor adequar ao seu currículo escolar ou propor algum tipo de jogo ou brincadeira para auxiliar na alfabe- tização de seus alunos.

O referencial Curricular (1998, p.28) nos apresenta a importância do brincar em sala de aula.

\begin{abstract}
O brincar apresenta-se por meio de várias categorias de experiên- cias que são diferenciadas pelo uso do material ou dos recursos predominantemente implicados. Essas categorias incluem: o movimento e as mudanças da percepção resultantes essencialmente da mobilidade física das crianças; a relação com os objetos e suas propriedades físicas assim como a combinação e associação entre eles; a linguagem oral e gestual que oferecem vários níveis de organização a serem utilizados para brincar; os conteúdos sociais, como papéis, situações, valores e atitudes que se referem à forma como 0 universo social se constrói; e, finalmente, os limites defini- dos pelas regras, constituindo-se em um recurso fundamental para brincar. Estas categorias de experiências podem ser agrupadas em três modalidades básicas, quais sejam, brincar de faz-de-conta ou com papéis, considerada como atividade fundamental da qual se originam todas as outras; brincar com materiais de construção e brincar com regras.
\end{abstract}

Estudos comprovam que os jogos e as brincadeiras contribuem de forma qualitativa para o desenvolvimento da fala e do físico individual de cada criança. Algumas situa- ções vividas no contexto escolar já têm sido mudadas, ou pelo menos já são normas a serem seguidas, pois o próprio Referencial Curricular Nacional (1998, p. 28) traz as contribuições que as brincadeiras oportunizam aos alunos inseridos no ambiente escolar.

Pela oportunidade de vivenciar brincadeiras imaginativas e criadas por elas mesmas, as crianças podem acionar seus pensamentos para a resolução de problemas que Ihes são importantes e signifi- cativos. Propiciando a brincadeira, portanto, cria-se um espaço no qual as crianças podem experimentar o mundo e internalizar uma compreensão particular sobre as 
Vygotsky (1991, p. 45) afima que já nas primeiras fases da infância a criança conhe- ce e explora seu mundo a partir dos brinquedos. (...) brincar é de suma importância para que a criança desenvolva seu lado cognitivo.

Fortuna (2000, p. 56) contribui para refletirmos quando afirma que as pessoas que se utilizam do ato de brincar aumentam muito seu campo intelectual. Sendo assim, o individuo tem condições de se apropriar do mundo de uma maneira mais ativa. E ainda, pode-se relatar o trabalho de Moyles (2002) que enfoca que o brincar para a criança não é só um meio para que se atinja a aprendizagem, mas também é uma forma de o adulto perceber dentro do âmbito escolar as necessidades que cada cri- ança tem em seu desenvolvimento.

Quando o conhecimento se dá conquistado através de métodos lúdicos apresenta muita satisfação por parte das crianças. Vygotsky (1991, p. 52) "ressalta que a brin- cadeira cria as zonas de desenvolvimento proximal e que estas proporcionam saltos qualitativos no desenvolvimento e na aprendizagem infantil". No âmbito escolar a brincadeira tem um papel fundamental porque quando a criança ou até mesmo o adulto brinca, suas emoções tomam forma e conduzem ao conhecimento e a assimi- lação dos conteúdos formais aplicados em todos os anos escolares.

Pereira (2004, p. 08) reforça esta afirmação quando relata que: "O ato de brincar é um legado de nossos antepassados. Faz parte da vida e sobrevivência de cada cri- ança, está no alicerce e cultura de um povo. Brinquedos e brincadeiras são patrimô- nios que pertencem à humanidade". humano

O Brincar é uma peça fundamental no desenvolvimento cognitivo do ser

\section{MÉTODOS DE ENSINO X JOGOS E BRINCADEIRAS}

Contexto Histórico dos Métodos Educacionais

Com a necessidade de buscar meios mais atrativos, divertidos e prazerosos para conquistar seus objetivos, o ser humano busca meios de tornar as situações diárias mais fáceis de serem realizadas. Com isso se percebe que 
sempre estávamos en- volto às brincadeiras, se analisarmos todas as civilizações cada uma delas apresen- tam algum tipo de brincadeira que faz parte da cultura local e que perpassa muitas vezes as fronteiras, assim é possível verificar ao longo do tempo que tanto crianças como adultos aparecem em imagens antigas se divertindo e brincando.

Nas antigas sociedades não havia distinção entre os participantes quando o assunto era divertimento, como conclui Ariès (1978). Nas sociedades anti- gas todos participavam das festas de maneira igualitária e os jogos eram formas de acirrar e melhorar os laços entre as pessoas que formavam aquele grupo social. Nota-se também que na antiguidade muitos dos jogos e brincadeiras eram resulta- dos de tradições, ou seja, essas atividades de divertimento faziam parte da cultura do povo.

No período medieval o número de crianças que conseguiam resistir aos primeiros anos de vida era muito reduzido, as taxas de mortalidade infantil eram altas, então a criança pouco aproveitava do que denominamos atualmente como uma boa e praze- rosa infância, as distinções entre a criança e o adulto quase não existiam, muito me- nos se tinha estudos voltados ao desenvolvimento infantil, a criança era vista como um adulto em miniatura que deveria cumprir com as mesmas obrigações impostas aos de mais idade, principalmente ao tratar-se do mundo do trabalho.

Ainda na Idade Média todas as ações do Homem eram voltadas aos ensinamentos e as determi- nações da Igreja. Denise Pozas (2011) nos traz que foram com os estudos científi- cos que a infância passa a ter outros olhares e ser considerada como um indivíduo que tem suas particularidades, diferenças e necessidades, deixa de contar com as comparações de adultos em miniatura e tem também inserido em seu desenvolvimento mento os jogos e brincadeiras, os quais não servem mais apenas ao divertimento e sim para um processo de crescimento físico e intelectual de uma criança.

Mas é somente no século XVIII que as questões da infância passam a indicar novos rumos e se tornam objetos de estudos científicos onde a criança começa a ser dife- renciada na sociedade, principalmente com relação ao seu desenvolvimento e o pa- pel que precisa conquistar no meio social. Assim 
ressalta Pozas (2011) que a crian- ça começa a ter seu desenvolvimento visto de um ângulo mais especifico e tem suas necessidades estudadas de uma forma mais ampla e condizente com suas reais ne- cessidades.

Segundo Pozas (2011) um dos precursores das atividades infantis com o uso da lu- dicidade é Froebel (1782-1852) e Kramer que denominam os períodos anteriores à escola como um jardim de infância. No Brasil pouco se tem de estudos sobre os brinquedos e brincadeiras do passado, e também com relação aos estudos voltados para a criança em pleno desenvolvimento, muitas das vezes as crianças não estuda- vam e tinha apenas o domingo livre para brincar, pois o país era composto de uma sociedade mais ruralista e desde muito cedo as crianças tinham que se inserir no mundo de trabalho do adulto.

O desenvolvimento cognitivo e psicomotor da criança passa a ser de maior preocu- pação no Brasil no final do século $X X$, pois até então, a maioria das escolas, principalmente as infantis eram um centro de assistencialismo. Tal mudança ocorre com as reformulações das leis educacionais e com os direitos e deveres das crianças propostos no Estatuto da Criança e do Adolescente e com isso as escolas e também os profissionais de educação passam a buscar meios mais lúdicos de motivar a aprendizagem e tornar a sala de aula um ambiente mais interessante e cativante, e o brincar assume um novo papel dentro do âmbito educacional, passa a ser visto como mais uma ferramenta de ensino e não mais como apenas um passatempo pra- zeroso para os momentos de descontração dos alunos.

Os documentos institucionais implicam em questões legais as quais apresentam me- didas de mudanças na Educação Infantil, principalmente, porque trata do ato de brin- car como um status que até alguns anos atrás não existia dentro do âmbito escolar. Tais amparos legais em defesa das crianças, fizeram com que os cursos de licencia- tura se reformulassem e atualmente a grande maioria dos professores das universi- dades apresenta aos seus acadêmicos métodos de ensino voltados à ludicidade, po- rém, muitos desses formados não aplicam esses métodos ao ingressarem nas escolas de todo o nosso país, principalmente, porque, os brinquedos e as brincadeiras precisam de muito mais tempo na preparação das aulas e também requer conhecimento 
sobre como trabalhar e inserir cada um deles ao decorrer do processo de ensino e de aprendizagem.

\section{JOGOS E BRINCADEIRAS NO DESENVOLVIMENTO DA CRIANÇA}

A inteligência é adaptação e a evolução do ser ocorre em estágios assim como o de- senvolvimento do corpo, as quais se modificam através de movimentos, que são eles dois, a assimilação e a acomodação, um se dá pelas ações externas e o outro pelas questões internas. Piaget (1966)

Nesta perspetiva, tudo se organiza através das atividades envolventes ao ser huma- no. Já Vygotsky (1989) analisa que o desenvolvimento humano se dá a partir das re- lações que cada indivíduo tem com o mundo em que vive, pois, o homem evolui com suas ações sócio-históricas.

Os estudos acadêmicos se apoiam nestas duas teorias que estruturam hipóteses para estudar como se dá o aprendizado pois fazem uma análise do ser humano, tan- to biologicamente como socialmente. A criança é um ser único e em constantes mu- danças e transformações, sejam elas psíquicas, motoras ou emocionais, cada qual evolui de uma forma distinta da outra, porém os jogos e as brincadeiras perpassam a teoria e apresentam às crianças métodos e formas de conhecer o mundo e tam bém se colocarem diante das condições afetivas e psicológicas transmitidas através da maneira em que vive um adulto, sendo assim um precisa do outro.

Nesta mesma visão, Pozas (2011) nos traz que é com a maturidade que cada pes- soa alcança a afetividade e que esta evolui e assim sendo é com o outro que todas essas situações afetivas adquirem significados devido às experiências vividas pelos indivíduos ao longo da vida. E ainda segundo Pozas (2011, p. 29) "essa construção de significados pela criança se dá pela intervenção do adulto e esse movimento se processa do social para o individual, e a intensidade e a diversidade dessas relações possibilitarão maior crescimento". Assim podemos refletir o quanto à criança se de-senvolve pelas influências do meio social em que vive.

Os jogos e as brincadeiras possibilitam a integração social mútua pois 
proporcionam um alto índice de socialização, envolvendo até os mais retraídos e contribuem muito para a construção social e psíquica de cada indivíduo. Para Teixeira (2003) a brinca- deira é fundamental para toda criança, pois brincando se socializa e constrói seu próprio mundo, e privar a criança das brincadeiras é violar a harmonia do seu desen- volvimento.

Dentro da escola, ambiente onde se dá a maior parte do aprendizado formal os jo- gos e as brincadeiras devem sempre fazer parte desse processo de a prendiaza- gem, pois, com as atividades lúdicas a criança é capaz de conhecer como funciona o mundo real. Na maioria das vezes as brincadeiras infantis estão correlacionadas com a forma de viver e se comportar dos adultos. Sem mencionar ainda que as brin - cadeiras proporcionam às crianças momentos de satisfação, prazer e alegria, então, o papel fundamental do lúdico é conduzir o trabalho pedagógico para métodos mais satisfatórios de aprendizagem, assim com a brincadeira o processo de desenvolvi - mento psíquico-motor da criança se dá com mais naturalidade, como nos traz Vygotsky (1984, p.114):

... O brincar e o brinquedo criam na criança uma nova forma de desejos. Ensinam-na a desejar, relacionando seus desejos a umfictício, ao seu papel no jogo e suas regras. Dessa maneira, as maiores aquisições de uma criança são conseguidas no brinque- do; aquisições que, no futuro, tornar-se-ão seu nível básico de ação e moralidade.

Os jogos e as brincadeiras no processo de alfabetização contribuem não somente para o desenvolvimento psíquico de uma criança mas também para a construção dos limites que deve ter cada ser humano, contando com regras e tempo, proporcio- nando ainda o desenvolvimento do autocontrole para conseguir brincar. Pozas (2011) acredita que a brincadeira é uma aprendizagem social que pressupõe rela- ções e encontros, esta seria, certamente, a forma mais interessante de se viabilizar o desenvolvimento cognitivo da criança.

\section{O JOGO E A BRINCADEIRA NO PROCESSO DE ALFABETIZAÇÃO}

Os jogos e as brincadeiras são heranças de nossos antepassados sendo 
resultados de processos históricos e culturais. Principalmente, as brincadeiras que na maioria das vezes são transmitidas através da história oral, ou seja, passada de geração em geração. $O$ ato de brincar é capaz de fazer com que a criança possa se identificar no meio social em que está inserida e assim o observa espiritualmente e corporalmen- te. Sendo que dessa maneira distingue o que tem significados positivos ou negativos para sua vida. Pozas (2011, p. 15) defende que: Brincar é uma das principais atividades da criança. É por meio da brincadeira que ela revive a realidade, constrói significados e os ressignifica momentos depois. Dessa forma, aprende, cria e se de- senvolve em todos os aspectos.

É através do jogo a criança se depara muitas vezes pela primeira vez com a frustra- ção da perda e percebe que na vida nem tudo se ganha e aprende que uns ganham enquanto outros perdem e nem por isso alguém perde sua vida porque foi derrotado em um determinado jogo. Assim estimulando o jogo estamos desenvolvendo na cri- ança fatores importantíssimos na sua vida que é o fato de "ganhar ou perder", pois o ser humano tende ao desejo apenas pelas vitórias e em hipótese alguma as derro- tas, portanto as crianças precisam compreender que nem sempre as pessoas saem vitoriosas em todas as situações.

Os jogos permitem com que uma criança se de- senvolva adequadamente e preencha suas necessidades simbólicas, fazendo de to- das essas ações fatores que os levam para seu próprio crescimento e conhecimento. O brincar com jogos ainda proporciona bons relacionamentos em grupos. Brincar e jogar é um meio que favorece relevantemente propiciando e interferindo muito as formas de uma criança se comunicar.

Brincar não é apenas um momento de prazer ou diversão para a criança, é também a construção do seu próprio conhecimento, tornando-se assim uma pessoa única, autônoma e capaz de futuramente tomar suas próprias decisões. Assim afirma Aranão (2004):

(...) é preciso que a criança explore o mundo em que vive e construa seu conhecimento a partir de suas interações com o meio e o professor deve ser o mediador dessa construção, proporcionando aos seus alunos o maior número possível de materiais necessários para enriquecer essas experiências. 
Assim, brincar e jogar é a peça fundamental para que a criança consiga atingir seu pleno desenvolvimento, seja ele psíquico, motor ou emocional, portanto, desenvol- ver-se integralmente.

\section{PROFESSOR COMO MEDIADOR DOS JOGOS E BRINCADEIRAS}

No ambiente da sala de aula as emoções fluem com muita intensidade propiciando o desenvolvimento afetivo natural. Assim sendo, escola não deve ter seu foco apenas na cabeça da criança pois como relata a Teoria de Wallon (1989) os pequenos não são dotados apenas de cérebro, então a escola não pode desenvolver apenas o in- telectual do ser humano.

É preciso considerar que as crianças têm corpo e emoção e há uma grande necessidade que os ambientes escolares busquem desenvolver o ser humano integralmente. Não que seja a escola responsável por todo o desenvolvimento de um pequeno ser em constante transformação, mas suas linhas pedagó- gicas precisam proporcionar meios para que o processo de desenvolvimento motor, emocional e intelectual decorra com mais qualidade e que priorize o desenvolvimen- to completo de uma criança.

Por essas razões as metodologias em sala de aula devem buscar meios, no qual a criança consiga se identificar como parte daquele processo de ensino e aprendizagem. Nessa questão vale notar a sustentação de Haetinger (2005, p. 83) O educador segue a evolução social e cultural de sua comuni- dade e do mundo, e deve utilizar todas as ferramentas e ideias disponíveis para aprender e ensinar, para tornar sua sala de aula o lugar mais encantador do mundo. Queremos a escola do encantamento onde todos se sintam incluídos.

Os jogos e as brincadeiras facilmente despertam nas crianças alegria e entusiasmo, o que nos faz perceber que ao brincar dentro do âmbito escolar seja a brincadeira di- rigida ou livre a criança é capaz de expressar suas emoções e consegue ainda mostrar ao mundo exterior seus desejos e suas expectativas. Com isso Porto (2003) afir- ma que com a brincadeira a criança age de maneira original e sem medo, nesse es- paço não há cobranças e é possível inventar e 
criar o que desejar. Dessa forma as relações entre o professor e o aluno passam a se modificar, pois, o professor conhece através dos jogos e das brincadeiras como seu aluno compreende os conteúdos e o mundo em que vive com o brincar das crianças o professor pode observar quais as lacunas ficaram em seu aluno durante o processo de ensino, e o que não conse - guiu compreender do conteúdo proposto e trabalhado.

O uso de jogos e brincadeiras possibilita que o professor tenha ciência de quais co- nhecimentos prévios o seu aluno já traz à escola e de que forma pode assimilar os conteúdos formais colocados pela instituição com sua experiência de vida. Assim re- lata o Referencial Curricular Nacional para a Educação Infantil (1998) que com as brincadeiras as crianças utilizam seus conhecimentos prévios para dar conceitos ao seu ato de brincar e que agem muitas vezes por imitação. Ao motivar a aprendiza- gem das crianças com a utilização de jogos, brincadeiras, músicas e brinquedos o professor consegue prender por mais tempo a atenção de seus alunos para os con- teúdos que pretende internalizar, pois, através do lúdico a criança consegue fazer diversas assimilações, então, determinado assunto pode ser tão teórico e abstrato, mas que com ludicidade podem ser ministrados com mais facilidade e compreendido com muito mais prazer e diversão.

Segundo Rizzi e Haydt (1987, p. 15):

O jogo é para a criança a coisa mais importante da vida. $O$ jogo é nas mãos do educador, um excelente meio de formar a crian- ça. Por essas duas razões, todo educador - pai ou mãe, pro- fessor, dirigente de movimento educativo deve não só fazer jo- gar como utilizar a força educativa do jogo.

Conduzir os conteúdos utilizando como métodos os jogos e brincadeiras além de to- das as contribuições já citadas para as relações entre os professores e os alunos, as aulas serão ministradas de maneiras mais lúdicas permitindo um maior desenvolvi- mento na aprendizagem das crianças, pois geralmente os jogos e as brincadeiras proporcionam desafiam aos alunos e os levam a pensar e raciocinar mais, seja na construção de brinquedos ou na forma como se joga cada jogo, é preciso dispor sempre de muita atenção. Por isso Moyles (2002, p. 100) argumenta: 
Uma vez que o brincar é um processo e não um assunto, é dentro dos assuntos que devemos ver o brincar como um meio de ensinar e aprender, e não como uma entidade separada. Devido à relevância do brincar para as crianças e sua motiva- ção, para ele, o brincar deve estar impregnado as atividades de aprendizagem apresentadas às crianças, em vez de ser consi- derado um estorvo ou atividade residual.

Os currículos norteiam os conteúdos que serão aplicados em sala de aula, porém é o professor o responsável pela escolha dos métodos e aplicação, o qual deve fazer do ato de brincar um instrumento para o processo de ensino e aprendizagem, os jo- gos e brincadeiras não podem ser separados do processo, ou seja, utilizá-los ape- nas como forma de recreação para os alunos. É como salienta Nicolau e Dias (2003) de que a brincadeira contribui muito para a aprendizagem infantil, porque são desafi- adores e propicia a melhora do raciocínio. Sendo assim os jogos e as brincadeiras contribuem para que 0 trabalho do professor alcance realmente seus objetivos, ou seja, para que seus alunos aprendam e se desenvolvam como verdadeiros cida- dãos, capazes de conviver adequadamente em sociedade e possibilita ainda a for- mação de uma pessoa com personalidade bem definida e um caráter que preserva ações de moralidade.

\section{A IMPORTÂNCIA DO BRINCAR}

Desde a primeira infância o brincar já faz parte da vivência da criança e já na primei- ra infância podemos observá-las brincando e se divertindo com suas mãozinhas e seus pezinhos, mostrando assim o quanto são divertidos aqueles momentos. Quan- do focamos nossas atividades e atitudes no prazer, as situações diárias se tornam mais facilitadas e alcançamos determinados equilíbrios, tanto corporais como inte- lectuais. Além, de ser natural o ato de brincar é também uma forma de se relacionar socialmente e culturalmente com o outro, sem contar que as brincadeiras motivam as atividades em grupos e ajuda uma criança ou mesmo um adulto a compreender a forma como pensa e age o outro indivíduo.

Já no início do século XX Froebel atentava seus estudos para o quanto é 
importante o brincar para uma criança, e Kishimoto (1998) cita em seu livro "O brincar e suas te- orias", um pouco dessas ideias desse autor. O qual dizia que brincar é algo inato do ser humano, até seu lado espiritual se alegra nos momentos de diversão propiciados pelos jogos e brincadeiras. Então, brincar contribui muito para o desenvolvimento bi- ológico do corpo e da mente e ainda favorece na construção da personalidade e do lado afetivo de cada ser humano.

A criança precisa sempre das brincadeiras, para que suas habilidades humanas se desenvolvam com bastante competência e que sejam suficientes para compreender o mundo real através do mundo do faz de con- ta, no qual a imaginação e a fantasia constroem um modo de vida mais adequado e compreensível ao espaço em que se insere esta criança.

Com o lúdico o conhecimento é construído de uma maneira mais divertida e prazero - sa, e quando o ser humano sente prazer seu corpo e sua mente busca e deseja ain- da mais essas situações de aprendizagem correlacionadas com o ato de brincar e se divertir. Portanto, criança que brinca aprende mais rapidamente e sem sofrimento e ainda prepara-se para enfrentar a vida adulta, a qual é tão diferente da sua.

\section{JOGOS E BRINCADEIRAS NA SALA DE AULA}

Os jogos e brincadeiras devem ser direcionados condizendo com a faixa etária ade- quada de cada criança para que assim haja maior participação, integração e motiva- ção. As regras devem ser preestabelecidas com clareza e em comum acordo para que desta forma haja incentivo á ordem, cumprimento das regras acordadas e boa convivência que certamente resultará na redução de casos de indisciplina. Através dos jogos há motivação para a concentração, e alunos mais atentos, pacientes e conseguem assim cumprir o que se determina, tanto no jogo como na convivência em grupo da sala de aula. Rizzo (2001, p. 40) complementa dizendo que "a atividade lúdica pode ser, portanto, um eficiente recurso aliado do educador, interessado no desenvolvimento da inteligência de seus alunos, quando mobiliza sua ação intelectu- al”. Destac-se aqui alguns jogos e brincadeiras motivadores para objetivo proposto: 
- A contação de histórias pode ser um excelente ponto de partida para as brincadeiras e jogos, considerando a historicidade trazida no contexto. Como pensa, Silva (1987) acrescenta que criar um "Cantinho da Leitura" em sala de aula e deixar que os alunos fiquem à vontade para ler, ir renovando o acervo de materiais com livros e revistas de interesse das crianças é uma atividade produtiva e que desperta para o gosto e hábito da leitura.

- Brincadeiras como a Amarelinha, que consiste em desenhar um espaço determinado no chão e que utiliza uma pedrinha para dar sequência à brincadeira. Modalidade que permite desenvolver nas crianças habilidades matemáti- cas devido à sequência numérica, coordenação motora, equilíbrio, atenção e concentração, o que fez com que os alunos prestassem mais atenção em sala de aula.

Freire (2006) reforça a ideia de que a exigência cognitiva da amarelinha não se refe - re apenas á ação da criança ao saltar de uma figura para a outra, mas também ao ato de lançar o objeto o que solicita coordenações motoras finas, referindo-se parti- cularmente á relação da criança com um espaço muito definido, que exige muita pre- cisão. O jogo da Queimada, passa a bola, peteca, corda e bandeirinha, permitem que as crianças desenvolvam a coordenação motora e a participação em grupo, principalmente, porque como são muito imaturos nesta fase da infância e também são mais egoístas por isso têm muitas dificuldades de desenvolver a socialização e o seu lado psíquico motor.

O Material dourado é um excelente recurso para o desenvolvimento cognitivo na lógica para desenvolver habilidades matemáticas, pois os alunos apresen- tavam muitas dificuldades na compreensão da sequência numérica, unidade, dezena, dúzia, centena, então, o material dourado foi muito útil para explicar e mostrar concretamente como funciona os números na matemática. Assim Co- menta Freitas (2004) que com o material dourado o aluno aprende conceitos abstratos da matemática brincando e de uma forma muito mais simples e de maneira significativa. Sendo assim o material dourado é um ótimo recurso di- dático, isso porque muitas vezes os conteúdos matemáticos são dificuldades 
de muitos alunos.

- O Alfabeto móvel que consiste em letras soltas (normalmente feitos em E.V.A), são recursos facilitadores no processo da alfabetização e que constro- em o conhecimento e habilidades leitoras e escritoras de maneira divertida e através de experiências coletivas entre os alunos.

- Os jogos com bolinhas de gude proporcionam o desenvolvimento da noção espacial, de lateralidade, coordenação motora fina, concentração e socialização.

- As brincadeiras de roda que resgatam a cultura e socializa por várias gerações como cita Nicolau e Dias (2003, p.78)

\begin{abstract}
As brincadeiras de roda assumem grande importância por levar a formação do círculo, situação em que pode-se comunicar frente a frente. Dando as mãos, as crianças formam um todo. Cantam, dançam ou tocam juntas; criam e seguem regras, exercitam textos e movimentos de forma coletiva, desenvolven- do a socialização e praticando democracia com valores de res- peito mútuo, cooperação e unidade de grupo.
\end{abstract}

- O jogo de Dominó desenvolve a noção de sequência numérica e raciocínio lógico.

- O jogo complete as palavras com a letra inicial faz com que a criança tenha consciência fonética e que desenvolva a percepção na formação inicial de cada palavra. São fichas com várias palavras, as quais não têm a letra inicial e o aluno tem que encontrar essa letra no meio de várias letras soltas. A trilha é um jogo que através de rimas os alunos descobrem as letras corretas que formam as palavras.

- O jogo Palavra dentro da Palavra consiste na busca de uma palavra dentro da outra. As cartelas são em formato de desenhos e os componentes têm que encontrar o nome das figuras nas cartelas de palavras.

É grande a gama de jogos lúdicos e pedagógicos que são disponibilizados 
também nas escolas públicas para incentivar novos métodos de ensino em sala de aula, es- ses jogos consistem em desenvolver na criança habilidades com a língua portugue- sa, pois cada um deles enfoca alguma modalidade como: consciência fonológica, lei- tura, escrita, ordem alfabética e motiva as crianças no processo linguístico da alfabe- tização.

- No jogo trocando a primeira letra os alunos montam a primeira palavra e a partir desta se consiste em montar outras palavras mudando a primeira letra, depois lê em voz alta as palavras montadas. Ganha o jogo quem monta mais palavras e consegue ler todas elas.

Além dos jogos pré-estabelecidos e determinados pelo professor é importante o brin- car livremente, tanto com jogos na brinquedoteca da escola como com brincadeiras que eles mesmos escolham. Como cita Pozas (2011, p. 95):

\begin{abstract}
A criação impulsiona o inusitado, desenvolvendo-o, fazendo com que surja também da vida, a aprendizagem social. A brin- cadeira livre se dirige e se refere a essa aprendizagem, na me- dida em que a criança aproveita situações do cotidiano para relê-las segundo suas próprias lentes.
\end{abstract}

A vida de uma criança é totalmente voltada para situações lúdicas e todos os dias precisam de brincadeiras, principalmente as livres, as quais fazem de sua imagina- ção um mundo real. A estruturação cognitiva proporcionada pelo ato de jogar e brin car possibilitará um aprendizado mais efetivo aos alunos tendo eles melhores condi- ções de apreender os conteúdos curriculares como afirma Piaget (2008, p. 158):

É pelo fato de o jogo ser um meio tão poderoso para a aprendi- zagem das crianças que em todo lugar onde se consegue transformar em jogo a iniciação à leitura, ao cálculo ou à orto- grafia, observa-se que as crianças se apaixonam por essas ocupações, geralmente tidas como maçantes.

É notório as expectativas dos alunos quando os jogos e brincadeiras são inseridos como recursos pedagógicos e estas expectativas podem ser revertidas em disciplina uma vez que começam a prestar mais atenção nas aulas para que 
chegue logo o tão esperado momento de jogar e brincar, não se dando conta que jogando e brin- cando estão aprendendo.

O processo de ensino e aprendizagem feito com métodos lúdicos apresenta resulta- dos positivos muito rapidamente, porém requer um grande esforço no trabalho do professor, pois o mesmo precisa procurar jogos e brincadeiras que se encaixem nos conteúdos a serem aplicados e muitas vezes é muito mais cômodo preparar uma aula na qual os alunos fiquem só sentados sem participação alguma no processo de ensino. Porém, é necessário que as crianças sejam construtoras ativas de seu co - nhecimento, pois com métodos mais lúdicos os alunos motivam-se mais para buscar e aprimorar os seus conhecimentos, pois quando a aula é divertida e prazerosa os conteúdos são aplicados e compreendidos com muito mais naturalidade e facilidade.

\section{CONSIDERAÇÕES FINAIS}

A reflexão proporcionada por essa pesquisa nos faz compreender o quanto as crian- ças e mesmo os adultos são muito destinados à dedicação total quando determina- dos fatores envolvem métodos lúdicos, sendo nítido no rosto de cada criança o quanto os jogos prendem sua atenção e como compreendem melhor e com mais fa- cilidade quando são motivadas. Os conteúdos curriculares propostos normalmente são apresentados de forma rígida e repetitiva assim não despertando prazer ou proporcionando desafios aos educandos tão pouco dentro da linguagem diária dos alunos, o que parece muito complexo e de difícil compreensão.

A pesquisa apresentou o quanto é importante e relevante à aplicação de métodos lúdicos em sala de aula, porém os métodos devem contar com metas bem definidas e delimitadas.

Foi possível também realizar a discussão sobre o quanto os jogos e brincadeiras contribuem para o desenvolvimento psíquico e motor de um aluno em fase de alfa- betização. Pois, os jogos e brincadeiras mostram a criatividade e a expressividade de uma criança, além de inseri-la de uma forma divertida no contexto social em que vive. Através dos jogos e das brincadeiras a criança faz 
do mundo da fantasia um palco, no qual a mesma encena fatos e atitudes que fazem parte da sua realidade diariamente, sendo assim consegue transformar problemas encontrados em sua vida em momentos de alegria e diversão.

E por fim, vale lembrar o que Pozas defende: "quem brinca mais aprende mais", isso devido ao fato de ser prazeroso, divertido, motivador e que se consolidam determi- nadas aprendizagens de forma natural, principalmente nessa fase tão encantadora, inocente e alegre como é a infância. 


\section{REFERÊNCIAS BIBLIOGRÁFICAS}

ANTUNES, C. Inteligências e competências. São Paulo: Ciranda Cultural, 2008.

ARANÃO, I. D. A Matemática Através de Brincadeiras e Jogos. 5. ed. Campinas: Papirus, 2004

ARIÉS, P. Historia social da criança e da família. Tradução de Dora Flaksman. 2. ed. Rio De Janeiro: Ltc, 2011. 196 p.

BRASIL, Ministério da Educação e do Desporto. Secretaria de Educação Fundamen- tal. Referencial Curricular Nacional para a Educação Infantil: documento intro- dutório. Brasília, 1998.

CARVALHO, M. Guia prático do alfabetizador. São Paulo: Ática, 2010.

FORTUNA, T. R. Sala de aula é lugar de brincar? Porto Alegre, 2000.

FREIRE, J. B. Educação de corpo inteiro: teoria e prática da Educação Física. São Paulo, 2006.

FREITAS, R. C. O. Um ambiente para operações virtuais com o material doura- do. Vitória: ES, 2004.

FROEBEL, F. The education of man. Ed.W. T. Harris. Trad. W.N. Hailmann. New York: D. Appleton. 1912.

GIL, A.C. Métodos e técnicas de pesquisa social. 5. ed. São Paulo: Atlas 1999.

GIL, A. C. Como elaborar projetos de pesquisa. 4ed. São Paulo: Atlas, 2009.

HAETINGER, M. G. O universo criativo da criança na educação. 2. ed. Porto Alegre: Instituto criar 2005.

HUIZINGA, J. Homo Ludens. São Paulo: Perspectiva, 2000. 
KISHIMOTO, T. M. O jogo e a educação infantil, 3.ed. São Paulo, Pioneira, 1998.

LUDKE, M.; ANDRÉ, M. E. D. A. Pesquisa em educação: abordagens qualitati- vas. São Paulo: EPU, 1986.

MOYLES, J.R. Só brincar? O papel do brincar na Educação Infantil. ;Porto Ale- gre: Artmed, 2002.

NICOLAU, M. L. M; DIAS, M. C. M. (orgs.). Oficinas de sonho e realidade na for- mação do educador da infância. Campinas: PAPIRUS, 2003.

PEREIRA, N. Brinquedoteca: jogos, brinquedos e brincadeiras. São Paulo: Pau- linas, 2004.

PIAGET, J. Psicologia e Pedagogia. Tradução: Dirceu A. Lindoso \& Rosa Maria R. da Silva.9. ed. Rio de Janeiro: Forense, 2008.

O nascimento da inteligência na criança. Rio de Janeiro: Guanabara, 1966.

PORTO, C. L. Brinquedo e brincadeira na brinquedoteca. In Kramer. S. Infância e produção cultural. Campinas: Papirus, 2003.

POZAS, D. A criança que brinca mais aprende mais: a importância da atividade lúdica para o desenvolvimento cognitivo infantil. Rio de Janeiro: Senac, 2011.

RIZZI, L.; HAYDT, R. C. Atividades lúdicas na educação da criança. São Paulo:

Ática, 1987.

RIZZO, G. Jogos inteligentes: a construção do raciocínio na escola natural. 3. ed. Rio de Janeiro: Berttrand Brasil, 2001.

SILVA, E. T. da. O Ato de Ler. 4 ed. São Paulo:Cortez, 1987.

TEIXEIRA, F.E.C (orgs.); MARTINEZ, A.M; REY, F.L.G et al. Aprendendo a aprender:guia de formação para professores das Séries Iniciais. Brasilia: Uniceub, 2003. 
VYGOTSKI, L. S. A formação social da mente. São Paulo: Martins Fontes, 1984.

. Pensamento e linguagem. São Paulo: Martins Fontes,1989.

A formação social da mente: o desenvolvimento dos processos psicológicos superiores. 4. ed. São Paulo: Martins Fontes, 1991.

WALLON, H. Origens do pensamento da criança. São Paulo: Manole, 1989.

http://portal.mec.gov.br/index.php?ption=com_docman\&view=dow nload\&alias $=5707-$ escola-ativa-alfabetizacao1educador\&Itemid=30192. 